\title{
Jump Diffusion Processes and Emerging Bond and Stock Markets: An Investigation Using Daily Data*
}

\author{
Mandeep S. Chahal \\ Enron Capital and Trade Resources, U.S.A. \\ Jun Wang \\ SAS Institute Inc., U.S.A.
}

The underlying stochastic processes that drive returns in several emerging bond and stock markets are investigated using the pure diffusion, the jump diffusion, the $\mathrm{ARCH}$ pure diffusion, and the $\mathrm{ARCH}$ jump diffusion models. The results indicate that jump diffusion models fit the data better than pure diffusion models. Possible sources and linkages of information surprises in emerging stock and bond markets are also investigated. Bond and stock returns of the same country exhibit simultaneous jumps, indicating a possible linkage of the two markets. U.S. equity returns respond to jumps in emerging bond markets but not to jumps in emerging stock markets (JEL C51, F36, G12, G14).

Keywords: emerging markets, $\mathrm{ARCH}$, jump diffusion, information surprises, distribution characteristics.

\section{Introduction}

Identifying the probability distribution that characterizes the return series of a financial asset has been an important task in empirical finance. It is becoming even more important with the increasing popularity of new risk measures such as Value at Risk (VAR). VAR is defined as the largest loss in portfolio value due to changes in market

${ }^{*}$ We thank G. Geoffrey Booth (Editor), Jayant Kale, Thomas Noe, Michael Rebello, Stephen Smith, Panayiotis Theodossiou (Managing Editor), two referees, the participants at the Department of Finance workshop of Georgia State University and the participants at the 1996 annual meeting of the Financial Management Association for their helpful comments. Any errors that remain are ours.

(Multinational Finance Journal, 1997, vol. 1, no. 3, pp. 169-197)

(C) by Multinational Finance Society, a nonprofit corporation. All rights reserved. DOI: $10.17578 / 1-3-1$ 
prices over a given period of time within a certain probability. VAR computations based on incorrect distributional assumptions do not provide an accurate picture of a portfolio's risk exposure, and may even induce faulty risk management decisions. ${ }^{1}$ Therefore, the first step in computing an accurate VAR measure is to find the distribution that closely approximates the dynamics of security prices/returns. ${ }^{2}$ This article, investigates the distributional characteristics of bond and stock returns in rapidly growing emerging markets.

Another reason to understand return distributions in these markets is their implications for optimal asset allocation. The mean-variance criterion is commonly used for international asset allocation. This criterion relies on the assumption that investors have a quadratic utility function or asset returns are normally distributed. The drawbacks of assuming a quadratic utility function for investors are well established. Moreover, the empirical results presented in this article provide strong evidence against normality of asset returns. Thus the optimality of the mean-variance strategy is in doubt. Therefore, it is necessary to devise new asset allocation strategies that account for the distribution of asset returns. $^{3}$

Moreover, emerging stock and bond markets have experienced significant growth in the past several years. ${ }^{4}$ U.S. companies, mutual funds, and pension funds have also been increasing their exposure to these markets. It is important to understand the dynamics of these emerging markets in order to provide better guidance to investors on risk management and portfolio allocation issues. ${ }^{5}$

Researchers have studied the return dynamics of U.S. markets and foreign exchange markets in great detail. It is well known that asset

1. For a discussion of how different distribution assumptions affect the VAR, see Duffie and Pan (1997).

2. An alternative way to measure the risk of extreme events is to look at the tails of the distribution; e.g., Embrechts, Resnick, and Samorodnitsky (1998) and Booth et al. (1997).

3. See Merton (1990) for an example of asset allocation within the jump-diffusion framework.

4. For example, capitalization in emerging market sovereign debt has grown over the period 1989 to 1993 from 50 billion to 1.2 trillion U.S. dollars. The volume of trade in sovereign debt issued by developing countries is currently 2.2 trillion U.S. dollars.

5. The mean and variance of returns in emerging capital markets are higher than those of developed markets; e.g., Harvey (1995) and Claessens and Gooptu (1993). 
returns have fatter tails to be successfully fitted by a normal distribution. A model that can capture the fatter tail effect is jump diffusion. Ball and Torous (1983) are the first to document that jump diffusion fits several U.S. stocks return series well. In a subsequent paper, the authors study the implications of their findings for option pricing (Ball and Torous [1985]). Jarrow and Rosenfeld (1984) investigate the implications of the jump diffusion model for capital asset pricing. Kim, Oh, and Brooks (1994) apply the jump diffusion model to individual U.S. stock prices and market indices. They find significant jumps in both return series.

A well-known characteristic of asset return dynamics is volatility clustering or conditional heteroskedasticity. ARCH (Autoregressive Conditional Heteroskedasticity) type models capture this effect well; see Bollerslev, Chou, and Kroner (1992) for a detailed review. A number of researchers find that a combination of $\mathrm{ARCH}$ and jump diffusion models provides a better modeling of return series. This is documented for the U.S. bond market by Das (1995) and for foreign exchange markets by Jorion (1988) and Johnson and Schneeweis (1994).

This article extends the investigation of the distribution of daily bond and stock returns in emerging markets using the pure diffusion (PD), jump diffusion (JD), ARCH pure diffusion (APD), and ARCH jump diffusion models (AJD). ${ }^{6}$ Various tests performed show that jump diffusion models fit the data better than pure diffusion models. These findings have serious implications in investment analysis and risk management of emerging markets. Because the normal distribution is not adequate to describe return dynamics of emerging markets, one needs to use jump diffusion as the underlying distribution to compare risk and reward. Specifically, VAR measures computed from a jump diffusion are generally higher than those computed from a pure normal distribution with equal total variance (Duffie and Pan [1997]). In addition, jump diffusion admits far more extreme values and thus requires a higher capital reserve to prepare for these extreme events.

Finally, the article investigates the possible sources of information surprises in emerging stock and bond markets. None of the studies mentioned above, with the exception of Das (1995), investigates this aspect of return dynamics. While Das (1995) focuses solely on the U.S.

6. Most of the early articles on emerging markets employ monthly data, thereby limiting the scope of questions/issues that can be addressed. Chahal, Rebello, and Smith (1995) use daily data for emerging stock and bond markets, but they only analyze the integration of emerging markets with the U.S. 
Treasury market, this article makes the connection between the bond market and the stock market of a home country. The results show that bond and stock returns of an emerging country are closely linked, as there exist simultaneous jumps in both return series. The returns of the U.S. equity market are connected with jumps in emerging bond markets but not in emerging stock markets. This finding is helpful in identifying risk exposure.

The bonds used in this study are highly liquid assets and popular trading instruments for investors who want exposure to emerging markets. The above results indicate that investors holding these bonds are exposed to not only risks in emerging markets but also risks in the U.S. equity market. Hence investors who seek exposure to only emerging markets have two alternatives: (1) a position in emerging bond markets plus a position to hedge away exposure to the U.S. equity market, or (2) a position in emerging stock markets.

The rest of the article is organized as follows. Section II describes the data and presents the statistical methodology. The empirical assessment of jump diffusion models and sources of jump risk is presented in section III. Section IV presents the conclusions.

\section{Data and Statistical Methodology}

\section{A. Data Description}

The data used in this study include bond and stock market index returns for six emerging economies (countries), the U.S., and a regional Latin American Equity index. The six countries are Brazil, Mexico, Morocco, Nigeria, Panama, Poland, and Venezuela. The data are collected at daily intervals and cover the period March 2, 1992 to May 10, 1994.

The bond data, obtained from First National Bank of Chicago's Emerging Markets Division, include daily prices for eleven bonds issued by the aforementioned countries. These prices are the average of bid and ask quotes as reported by Reuters at 4 p.m. Eastern Standard Time. Six of the bonds are Brady bonds. That is, they are denominated in U.S. dollars and their principal, and in many case their interest, is collateralized by U.S. Treasury zero-coupon bonds. The remaining five bonds are also dollar denominated, but they differ from Brady bonds in that neither principal nor interest is backed by specific collateral. These bonds are traded in New York and London. Because of the market 
location, collateral characteristics, and dollar-denomination, these eleven bonds are the most liquid emerging market instruments. Appendix A provides additional information on the eleven bonds.

Continuously-compounded daily returns are computed from the bond prices and accrued interest using formula ${ }^{7}$

$$
X_{t}=\ln \left(\frac{P_{t}+A I_{t}}{P_{t-1}+A I_{t-1}}\right) \text {, }
$$

where $X_{t}$ is the return for trading day $t$, "In" is the natural logarithm, $P_{t}$ is the closing price at time $t$, and $A I_{t}$, is the accrued interest during period $t-1$ to $t$.

The stock data include daily values for a U.S. equity index (USR), a regional Latin American equity index (LAMR), and six market equity indices; one for each of the aforementioned countries. The USR is a value-weighted index of all equity securities on the CRSP tapes and accounts for dividends. The LAMR is a value weighted stock return index (by market capitalization) of seven Latin American countries, including Argentina, Brazil, Mexico, Peru, and Venezuela. The remaining six indices are value-weighted indices of actively traded stocks and include dividends. The daily values of all seven indices are converted into U.S. dollars using the Reuter's exchange rate at 3 p.m. Eastern Standard Time. ${ }^{8}$ Daily continuously-compounded (U.S. dollar) returns are calculated using the formula

$$
X_{t}=\ln \left(\frac{P_{t}}{P_{t-1}}\right),
$$

where $P_{t}$ is the price of the stock index at time $t$. Note that the prices

7. Holders of bonds issued by Poland and Panama did not receive interest payments over the sample period, thus $A I_{t}=0$ for these bonds.

8. Stock data for the six emerging economies and the LAMR were obtained from the Morgan Stanley Capital International Emerging Markets Database (MSCI). The dividend adjustment used by MSCI is as follows: (1) In the period between ex date and the date of dividend reinvestment, a dividend reinvestment is a component of the index return. (2) Dividends are deemed received on the payment date. (3) To determine the payment date, a fixed time lag is assumed to exist between the ex date and the payment date. This time lag varies by country and is determined in accordance with general practice within that market. (4) Reinvestment of dividends occurs at the end of the month in which the payment date falls. 
used to compute these returns are the official closing prices in the dominant stock exchanges in each country.

Additional U.S. data includes the returns on the Federal Funds Rate $(F F R)$, which were obtained from the Federal Reserve Bank of Atlanta.

\section{B. Statistical Methodology}

Table 1 presents various distribution statistics of daily returns for the bond and equity indices in the six emerging markets (countries), the Latin American index and the U.S. These statistics help to motivate the jump diffusion framework for modeling returns. One common feature of all bond and stock series examined is the large excess kurtosis, which is statistically significant at the five percent level. Note that excess kurtosis is higher for bond returns than for stock returns.

Another common feature is that there are more extreme values than could be justified by a normal distribution of the same mean and variance. For example, the bond Brazil Exit has sixteen daily returns that are at least three standard deviations away from the mean and four returns that are at least five standard deviations away. These two numbers represent $2.95 \%$ and $.74 \%$ of all the observations. However, under the assumption that the return series is normally distributed, the probability of having one draw that is three standard deviations away is $.27 \%$ and the probability of a draw five deviations away is $.000057 \%$. Clearly, the return series has too many extreme values to be generated by a normal distribution.

The fat tails in the data can be modeled using a stochastic volatility process, such as a ARCH or a jump diffusion process. ${ }^{9}$ It is well recognized that conditional volatility models capture the volatility clustering property of the data well, but they do not fully account for the fat-tailed properties of the data; e.g., Baillie and Bollerslev (1989) for a study of the U.S. financial markets. The jump diffusion framework, on the other hand, models the data as a mixture of routine movements and random bursts of jumps. This provides flexibility in accommodating extreme values in the data and thus captures the fat-tailed properties. However, since conditional autoregressive heteroskedasticity (volatility) is not modeled in the pure jump diffusion setting, the volatility clustering effect is not captured by this model. Overall, one may expect that a combination of jump diffusion and ARCH models provides the

9. The skewed generalized $\mathrm{t}$ (GT) distribution, developed by Theodossiou (1998), can also be used to model the fat tails and skewness in financial data. 
TABLE 1. Summary Statistics for Daily Bond and Equity Index Returns

\begin{tabular}{|c|c|c|c|c|c|c|c|}
\hline \multicolumn{8}{|l|}{ A. Bond Returns } \\
\hline Bond & Nobs & $\begin{array}{l}\text { Mean } \\
\times 10^{-5}\end{array}$ & $\begin{array}{l}\text { Standard } \\
\text { Deviation }\end{array}$ & Skewness & $\begin{array}{l}\text { Excess } \\
\text { Kurtosis }\end{array}$ & $\begin{array}{l}\text { Nobs } \\
(>3 \mathrm{se})(\end{array}$ & $\begin{array}{l}\text { Nobs } \\
(>5 \mathrm{se})\end{array}$ \\
\hline Brazil Exit & 542 & -30.7 & .0124 & $-1.48 *$ & $11.31 *$ & 16 & 4 \\
\hline Brazil IDU & 383 & 47.9 & .0104 & $-.62 *$ & $4.55^{*}$ & 6 & 1 \\
\hline Mexico Discount & 545 & 3.3 & .0066 & $-.59 *$ & $8.99 *$ & 15 & 1 \\
\hline Mexico Par & 545 & 0.3 & .0088 & -1.18 & $8.07 *$ & 16 & 1 \\
\hline Morocco & 547 & 92.7 & .0113 & $-.85^{*}$ & $4.82 *$ & 10 & 1 \\
\hline Nigeria Par & 547 & 12.7 & .0144 & $-.54 *$ & $10.09 *$ & 15 & 2 \\
\hline Panama & 544 & 130.9 & .0246 & $-1.52 *$ & $14.55^{*}$ & 12 & 3 \\
\hline Peru CB & 522 & 179.5 & .0310 & $-1.09 *$ & $9.38 *$ & 10 & 2 \\
\hline Poland DDRA & 547 & 119.1 & .0206 & $-.68 *$ & $6.82 *$ & 11 & 2 \\
\hline Venez. Discount & 547 & -49.3 & .0142 & $-.42 *$ & $4.36^{*}$ & 11 & 0 \\
\hline Venez. Par & 549 & -38.4 & .0134 & $-.80 *$ & $6.60 *$ & 11 & 2 \\
\hline \multicolumn{8}{|l|}{ B. Equity Returns } \\
\hline $\begin{array}{l}\text { Equity } \\
\text { Index }\end{array}$ & Nobs & $\begin{array}{l}\text { Mean } \\
\times 10^{-5}\end{array}$ & $\begin{array}{l}\text { Standard } \\
\text { Deviation }\end{array}$ & Skewness & $\begin{array}{l}\text { Excess } \\
\text { Kurtosis }\end{array}$ & $\begin{array}{l}\text { Nobs } \\
(>3 \mathrm{sd})\end{array}$ & $\begin{array}{l}\text { Nobs } \\
(>5 \mathrm{sd})\end{array}$ \\
\hline USR & 550 & 26.5 & .0055 & $-.40 *$ & $2.47 *$ & 7 & 0 \\
\hline LAMR & 549 & 33.4 & .0130 & $-.44 *$ & $2.24 *$ & 7 & 1 \\
\hline Argentina & 549 & -7.5 & .0259 & $-.34 *$ & $1.91 *$ & 6 & 0 \\
\hline Brazil & 549 & 38.8 & .0315 & $-.31 *$ & $0.68 *$ & 4 & 0 \\
\hline Mexico & 549 & 21.0 & .0162 & -.059 & $1.60 *$ & 7 & 0 \\
\hline Peru & 340 & 133.2 & .0230 & $-.49 *$ & $2.05^{*}$ & 4 & 0 \\
\hline Poland & 340 & 534.9 & .0377 & $-.30 *$ & $2.13 *$ & 3 & 0 \\
\hline Venezuela & 340 & -104.6 & .0208 & 0.055 & $4.33^{*}$ & 5 & 0 \\
\hline
\end{tabular}

Note: The columns Nobs ( $>3 \mathrm{sd}$ ) and Nobs ( $>5 \mathrm{sd}$ ) give the number of returns that are at least three and five standard deviations from the mean, respectively. The sample period is March 2, 1992 to April 8, 1994. *Statistically significance at the five percent level. USR is for U.S. index returns and LAMR is for Latin American Equity Index returns. All equity indices are expressed in U.S. dollars and account for dividends.

best fit to the data series.

According to table 1, the data exhibit significant skewness. All the data series, with the exception of equity indices for Mexico and Venezuela, exhibit significant skewness at the five percent level. ARCH models allow the volatility, or conditional heteroskedasticity, to vary over time, thus making it easier to match the fourth moment or kurtosis to the data. Nevertheless, time-varying conditional volatility has a limited effect on the third moment or skewness. Hence ARCH 
models cannot fit all kinds of skewness in the data.

On the other hand, jump diffusion models have the advantage of capturing skewness. The reason is that jump diffusion processed model the data as normal fluctuations plus random arrivals of big jumps. The sizes of those jumps are also random. Changing the mean of the jump size and the arrival probability affects the mean and the skewness of the distribution. In general, it is easier to match skewness of the data with jump diffusion models than with conditional heteroskedasticity models.

Following Jorion (1988) and Das (1995), we estimate different return specifications using maximum likelihood estimation. We study four models, the pure diffusion (PD), the pure diffusion with timevarying conditional heteroskedasticity (APD), the jump diffusion (JD), and the jump diffusion with time-varying conditional heteroskedasticity (AJD). Note that the first three models are nested within the last model.

The pure diffusion model assumes that returns are normally distributed with mean $k$ and variance $\sigma^{2}$, i.e.,

$$
X(t)=k+\sigma z(t)
$$

where $\mathrm{z}(t)$ is an i.i.d. (identically and independently distributed) standard normal error; i.e., it has mean zero and variance one. In the jump diffusion framework, the return process is modeled as

$$
X(t)=k+\sigma z(t)+J \times y,
$$

where $z(t)$ has the same properties as in (1), and $J$ is a Bernoulli random variable taking the value of one $(J=1)$ in the case of a jump and the value of zero $(J=0)$ otherwise. The probability of a jump is $h$, and consequently the probability of no jump is $1-h$. The random variable $y$ is normally distributed with mean $\mu$ and variance $\gamma^{2}$ and it is stochastically independent of $z(t)$. The above jump diffusion process can also be viewed as a mixture of two normal distributions; see Akgiray and Booth (1987). Moreover, note, that when $h=0$, equation 2 simplifies to equation 1 . In this respect, the pure diffusion process is nested within the pure jump diffusion process. ${ }^{10}$

10. The estimation method for the jump-diffusion process is based on the Bernoulli approximation first employed by Ball and Torous (1983) and more recently by Das (1995). It is well known that the Bernoulli process is a stable approximation of the Poisson process and converges to it in the limit. This methodology differs from that employed by Jorion 
In the case of the AJD

$$
\begin{gathered}
X(t)=k+\sigma(t) z(t)+J \times y, \text { and } \\
\sigma^{2}(t)=a_{0}+a_{1}[X(t-1)-k]^{2},
\end{gathered}
$$

where $\sigma^{2}(t)$ is the conditional variance of returns specified as a function of past volatility shocks or a first order ARCH process. Equation 4 captures time variation in conditional heteroskedasticity which is responsible for portion of kurtosis in the data. Note that when $\sigma^{2}(t)=\sigma^{2}$, AJD reduces to that of a JD model.

To further investigate the sources of jumps, the jump variable $\mu$ is specified as a function of contemporaneous $(t)$, one-day lagged and oneday forward returns from the bond and stock markets in the home and foreign markets. Specifically, for the emerging bond series the jump variable $\mu$ is specified as

$$
\begin{aligned}
\mu(t)=c_{0} & +c_{1} F F R_{t}+c_{2} F F R_{t-1}+c_{3} F F R_{t+1} \\
& +d_{1} H_{S R_{t}}+d_{2} H S R_{t-1}+d_{3} H S R_{t+1} \\
& +e_{1} U_{S R_{t}}+e_{2} U_{S R_{t-1}}+e_{3} U_{S R_{t+1}},
\end{aligned}
$$

where $F F R_{t}$ is the Federal Funds Rate, $H S R_{t}$ is the home country stock index return, and $U S R_{t}$ is the U.S. equity stock index return. For the emerging equity indices, the $\mu$ is specified as

$$
\begin{aligned}
\mu(t)=c_{0} & +c_{1} F F R_{t}+c_{2} F F R_{t-1}+c_{3} F F R_{t+1} \\
& +d_{1} H B R_{t}+d_{2} H B R_{t-1}+d_{3} H B R_{t+1} \\
& +e_{1} U_{S R_{t}}+e_{2} U_{S R_{t-1}}+e_{3} U_{S R_{t+1}}
\end{aligned}
$$

where $H B R_{t}$ is the home country bond return and $F F R_{t}$ and $U S R_{t}$ are as defined previously. The $F F R_{t}$ and $U S R_{t}$ variables can be viewed as 
proxies for the risk-free rate and U.S. market risk and the $H B R_{t}$ variable is used as a proxy for home country risk. By identifying the factors that contribute significantly to the jump size, we can study the linkages in jumps across markets and shed light on the possible sources of jumps.

These PD, JD, APD, and AJD as well as the various specifications for the jump parameter $\mu$ are estimated using the maximum likelihood estimation method. The estimation involves maximization of the following general log-likelihood function

$$
\begin{aligned}
L \equiv \max _{\varphi} \sum_{t=1}^{T} \ln \left\{\frac{1-h}{\sqrt{2 \pi \sigma(t)^{2}}} \exp \left(-\frac{1}{2} \frac{(X(t)-k)^{2}}{\sigma(t)^{2}}\right)\right. \\
\left.+\frac{h}{\sqrt{2 \pi\left(\sigma(t)^{2}+\gamma^{2}\right)}} \exp \left(-\frac{1}{2} \frac{(X(t)-k-\mu(t))^{2}}{\left(\sigma(t)^{2}+\gamma^{2}\right)}\right)\right\}
\end{aligned}
$$

with respect to the parameter vector (space) $\varphi=[k, \mu, \cdots] .{ }^{11}$ Note that PD, JD, and APD are nested within the AJD, and as such their likelihood functions are special cases of (7). Specifically, in the case of PD and APD $h=\mu=0$, in the case of PD and $\operatorname{JD} \sigma^{2}(t)=\sigma^{2}$. Moreover, in JD and AJD $\mu(t)$ may be specified as constant over-time.

The comparison between nested models can be accomplished by using the likelihood ratio (LR) test statistic

$$
\mathrm{LR}=-2 \times\left(L_{\mathrm{E}}-L_{\mathrm{N}}\right)
$$

where $L_{\mathrm{E}}$ and $L_{\mathrm{N}}$ are the values of the log-likelihood functions of the enlarged and nested models as defined in (7). The LR statistic follows a $\chi^{2}$ distribution with degrees of freedom equal to the difference in the number of parameters estimated under the two specifications. Another measure to compare the fit of these models is the Schwarz criterion (Schwarz [1978]), defined as

$$
\mathrm{SC}=-2 \times L(\phi \mid X)+K \log T
$$

where $L(\varphi \mid X)$ represents the log-likelihood function of the parameter

11. Appendix B gives the derivation of the log-likelihood function in (7). 
vector $\varphi$ given the data $X, K$ is the number of parameters to be estimated, and $T$ is the number of observations. The Schwarz criterion accommodates the tradeoff between better fit and more parameters by penalizing the model with the larger number of parameters. The most probable model is the one with the smallest SC value. The SC is useful for comparing non-nested models, such as the JD and APD.

\section{Empirical Results}

\section{A. Comparison of the Four Diffusion Models}

Table 2 presents the results for the pure diffusion (PD), jump diffusion (JD), ARCH pure diffusion (APD), and ARCH jump diffusion (AJD) models for emerging country bonds. ${ }^{12}$ Based on the log-likelihood ratio (LR) test statistic, the AJD model appears to provide the best fit to the data. The only exception is the Mexico Discount bond. These results are also supported by Schwarz criterion (SC); that is, in all cases the SC value is the lowest for the AJD models compared to the other three models. Moreover, the SC criterion indicates that out of the non-nested models, the JD model provides a better fit to the data than the APD model. The latter result implies that time-varying volatility alone cannot explain the extreme values.

Table 3 presents the results of the four models for emerging market stock indices and the U.S. value-weighted equity index. The improvement of fit is observed when switching from conditional volatility models to jump diffusion models. For example, the jump diffusion model outperforms the pure diffusion model based on both the log-likelihood ratio tests and the Schwarz criterion. Between the two non-nested models, jump diffusion outperforms ARCH diffusion based on the Schwarz criterion (except for LAMR). In general, jumps need to be included in the model of return process to have a better fit. ${ }^{13}$

Several interesting results can be found for both emerging bond and stock markets from tables 2 and 3 respectively. The estimates of variance $\left(\sigma^{2}\right)$ in the pure diffusion model are higher than those obtained

12. A Tuesday effect for several bonds exists. However, the results are similar to the ones obtained without day-of-the-week effects; results available upon request.

13. In some cases, the AJD did not improve upon the fit provided by the jump diffusion model. The reason is that the former model uses at least one less observation. 
TABLE 2. Estimation of Jump Diffusion Models Bond Returns

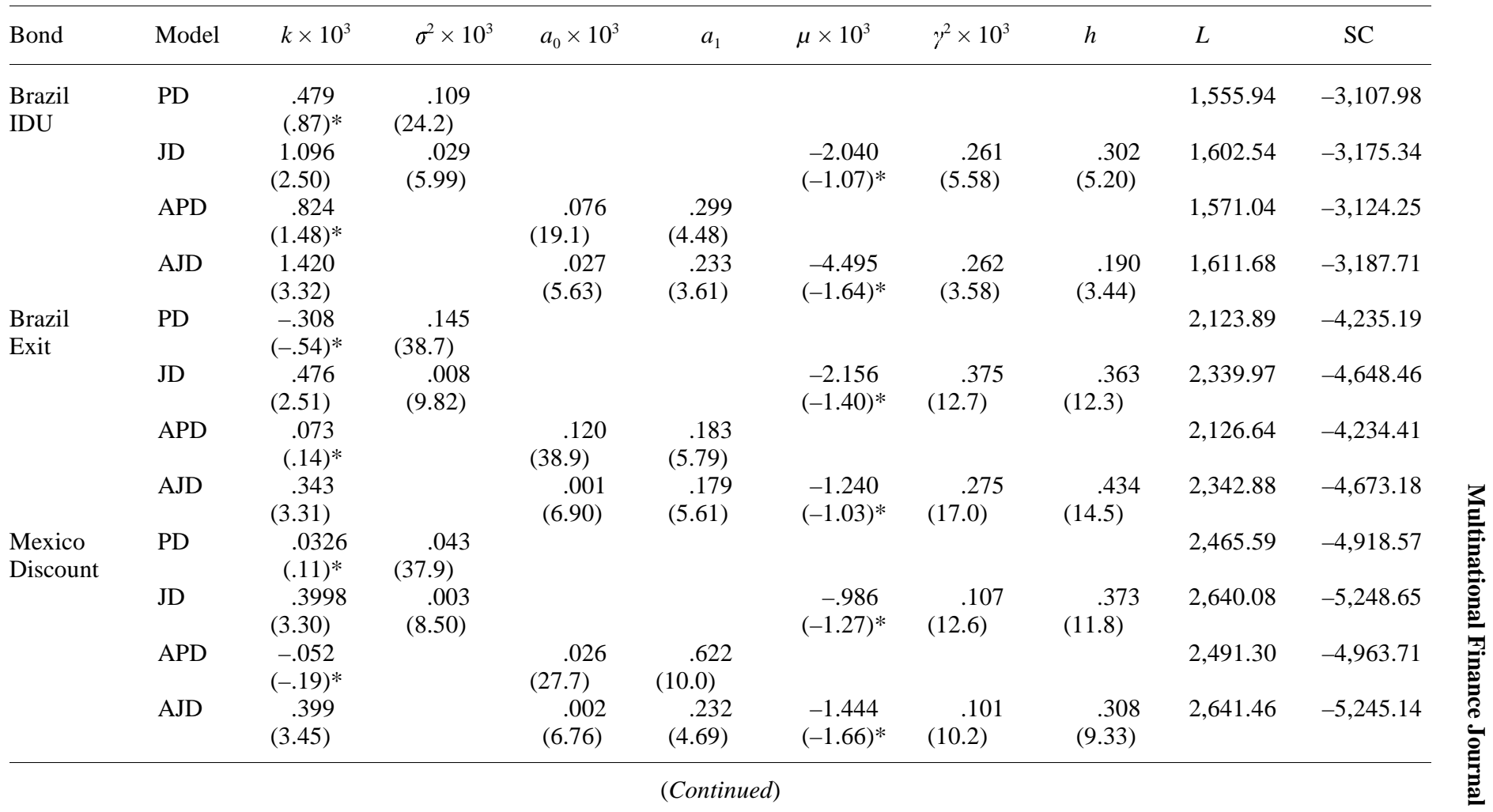


TABLE 2. (Continued)

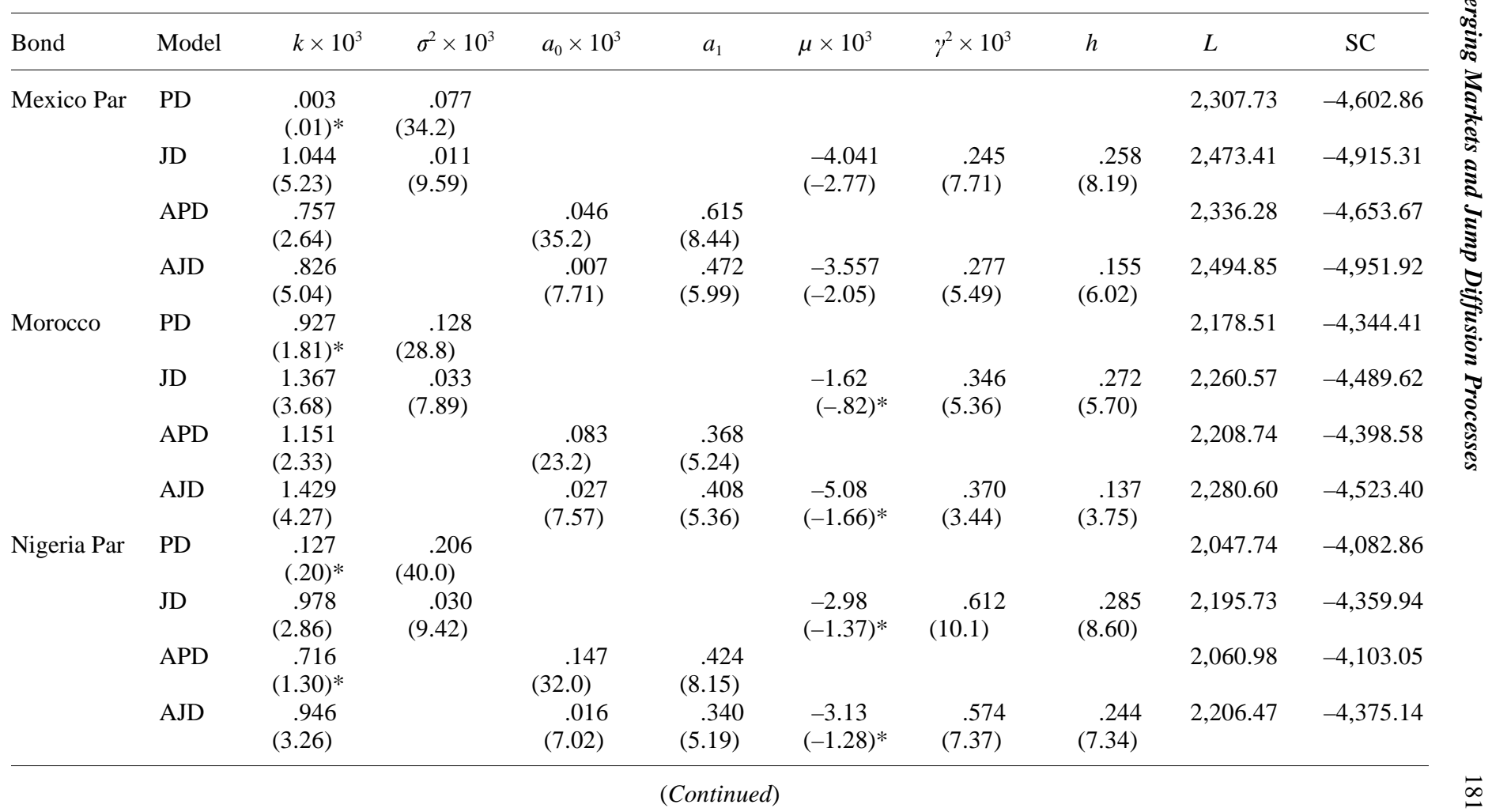




\section{TABLE 2. (Continued)}

\begin{tabular}{|c|c|c|c|c|c|c|c|c|c|c|}
\hline Bond & Model & $k \times 10^{3}$ & $\sigma^{2} \times 10^{3}$ & $a_{0} \times 10^{3}$ & $a_{1}$ & $\mu \times 10^{3}$ & $y^{2} \times 10^{3}$ & $h$ & $L$ & $\mathrm{SC}$ \\
\hline \multirow[t]{4}{*}{ Panama } & PD & $\begin{array}{c}1.309 \\
(1.15)^{*}\end{array}$ & $\begin{array}{l}.605 \\
(43.8)\end{array}$ & & & & & & $1,743.65$ & $-3,474.70$ \\
\hline & JD & $\begin{array}{l}-.021 \\
(.00)^{*}\end{array}$ & $\begin{array}{l}.0001 \\
(.00)^{*}\end{array}$ & & & $\begin{array}{c}.873 \\
(.00)^{*}\end{array}$ & $\begin{array}{l}1.100 \\
(2.43)\end{array}$ & $\begin{array}{c}.877 \\
(18.1)\end{array}$ & $2,212.12$ & $-4,392.75$ \\
\hline & APD & $\begin{array}{c}2.870 \\
(2.51)\end{array}$ & & $\begin{array}{c}.487 \\
(32.7)\end{array}$ & $\begin{array}{r}.375 \\
(7.14)\end{array}$ & & & & $1,735.69$ & $-3,452.50$ \\
\hline & AJD & $\begin{array}{c}-.031 \\
(-.37)^{*}\end{array}$ & & $\begin{array}{c}.000 \\
(.00)\end{array}$ & $\begin{array}{r}.176 \\
(4.82)\end{array}$ & $\begin{array}{c}.953 \\
(.39)^{*}\end{array}$ & $\begin{array}{c}1.179 \\
(19.7)\end{array}$ & $\begin{array}{c}.656 \\
(16.9)\end{array}$ & $2,339.09$ & $-4,640.41$ \\
\hline \multirow[t]{4}{*}{ Peru CB } & PD & $\begin{array}{c}1.795 \\
(1.25)^{*}\end{array}$ & $\begin{array}{c}.961 \\
(36.3)\end{array}$ & & & & & & $1,552.30$ & $-3,092.08$ \\
\hline & JD & $\begin{array}{c}.297 \\
(.02)^{*}\end{array}$ & $\begin{array}{c}.000 \\
(.00)^{*}\end{array}$ & & & $\begin{array}{l}1.074 \\
(.06)^{*}\end{array}$ & $\begin{array}{c}1.399 \\
(18.3)\end{array}$ & $\begin{array}{c}.944 \\
(24.5)\end{array}$ & $1,716.21$ & $-3,401.38$ \\
\hline & APD & $\begin{array}{c}3.398 \\
(2.71)\end{array}$ & & $\begin{array}{l}.582 \\
(21.3)\end{array}$ & $\begin{array}{r}.513 \\
(8.60),\end{array}$ & & & & $1,577.76$ & $-3,096.76$ \\
\hline & AJD & $\begin{array}{c}.054 \\
(.13)^{*}\end{array}$ & & $\begin{array}{c}.000 \\
(.00)\end{array}$ & $\begin{array}{c}.198 \\
(3.76)\end{array}$ & $\begin{array}{l}1.449 \\
(.65)^{*}\end{array}$ & $\begin{array}{c}1.160 \\
(19.7)\end{array}$ & $\begin{array}{c}.804 \\
(21.1)\end{array}$ & $1,765.54$ & $-3,493.56$ \\
\hline \multirow[t]{4}{*}{$\begin{array}{l}\text { Poland } \\
\text { DDRA }\end{array}$} & PD & $\begin{array}{c}1.191 \\
(1.32)^{*}\end{array}$ & $\begin{array}{c}.424 \\
(33.7)\end{array}$ & & & & & & $1,850.62$ & $-3,688.62$ \\
\hline & JD & $\begin{array}{c}1.489 \\
(2.23)\end{array}$ & $\begin{array}{r}.135 \\
(8.97)\end{array}$ & & & $\begin{array}{l}-1.47 \\
(-.33)^{*}\end{array}$ & $\begin{array}{c}1.424 \\
(5.43)\end{array}$ & $\begin{array}{r}.202 \\
(5.26)\end{array}$ & $1,933.54$ & $-3,835.56$ \\
\hline & APD & $\begin{array}{c}-.518 \\
(-.70)^{*}\end{array}$ & & $\begin{array}{l}.260 \\
(20.7)\end{array}$ & $\begin{array}{c}.568 \\
(7.53)\end{array}$ & & & & $1,869.40$ & $-3,719.91$ \\
\hline & AJD & $\begin{array}{c}1.756 \\
(2.80)\end{array}$ & & $\begin{array}{c}.109 \\
(7.97)\end{array}$ & $\begin{array}{c}.278 \\
(4.41)\end{array}$ & $\begin{array}{l}-6.77 \\
(-1.08)^{*}\end{array}$ & $\begin{array}{c}1.687 \\
(3.73)\end{array}$ & $\begin{array}{r}.123 \\
(3.92)\end{array}$ & $1,945.91$ & $-3,854.01$ \\
\hline
\end{tabular}


TABLE 2. (Continued)

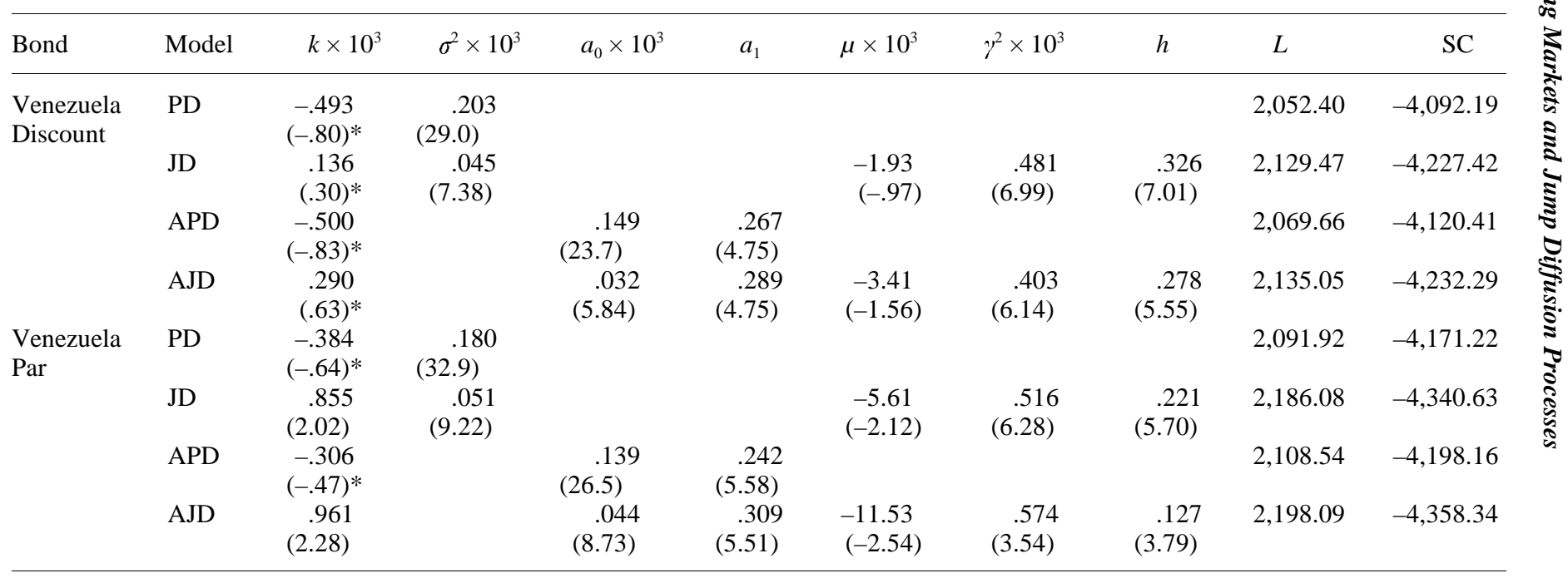

Note: PD is for pure diffusion, JD for jump diffusion, APD for ARCH pure diffusion, and AJD for ARCH jump diffusion. The AJD model is specified as $X(t)=k+\sigma z(t)+J \times y, \sigma^{2}(t)=a_{0}+a_{l}(X(t-1)-k)^{2}$, where $z(t)$ is an i.i.d. standard normal error, $J$ is a Bernoulli random variable $(J=1$ with probability $h$ and $J=0$ with probability $1-h)$, and $y$ is normally distributed with mean $\mu$ and variance $\gamma^{2}$. For the PD and APD models $h=0$, and for the JD model $\sigma^{2}(t)=\sigma^{2}$. L is for the log-likelihood and SC for the Schwartz criterion. The estimation of the parameters of the four diffusion processes is based on the maximum-likelihood estimation method. t-statistics are presented in the parentheses. *Statistically insignificant at the five percent level. The data are daily and cover the period March 2, 1992 to April 8, 1994 
in the jump diffusion model. This is expected because the variance $\left(\sigma^{2}\right)$ in the pure diffusion case captures the entire volatility of the series while the jump diffusion model assigns a portion of this volatility to the jump component. The mean jump sizes $(\mu)$ are, in general, statistically different from zero. Since the model does not distinguish between positive and negative jumps, the observed mean jump size can simply be an outcome of positive and negative jumps canceling each other during the sample period. ${ }^{14}$ However, the mean jump sizes are of the same magnitude as the means of pure diffusion $(k)$. This corresponds to our earlier conjecture, that jump diffusion allows more flexibility in modeling the skewness of the data. As expected, the ARCH parameters are statistically significant for all return series. This is evidence that volatility in the emerging markets is time-varying and there is volatility clustering in these series.

The estimates of the jump variance $\left(\gamma^{2}\right)$ provide additional insight. First note that in a pure jump model, the jump variances are generally higher than the variances of the diffusion components. Such large jump variations enable jump diffusion models to fit extreme values better than models without a jump. For the bonds (table 2), the estimated standard deviation of jump size $(\gamma)$ is highest for Poland DDRA and lowest for Mexico Discount. Further, the estimated arrival probability of a jump per day is highest for Peru and lowest for Morocco. In the case of country stock indices, the jump standard deviation is highest for the Polish stock index and lowest for the Mexican stock index. The estimate of jump standard deviation is lower for the emerging market equity index and for the U.S. value weighted index.

The U.S. equity markets display lower jump variations and lower arrival probability than the Latin American equity market index (as well as individual countries in the sample). This is expected since diversification at the index level reduces the overall jump risk and the U.S. market is less volatile than these emerging markets. However, note that the jump arrival rate and the jump variance of the U.S. valueweighted return and Latin American index are significantly different are from zero. This implies that jump risk may not be diversifiable, as there exist significant jumps in the return series of the portfolios. This finding supports the result of Kim, Oh, and Brooks (1994).

14. This conjecture is supported when we allow mean jump size to be a function of some exogenous factors in the later sections. 
TABLE 3. Jump Diffusion Estimation for Equity Index Returns

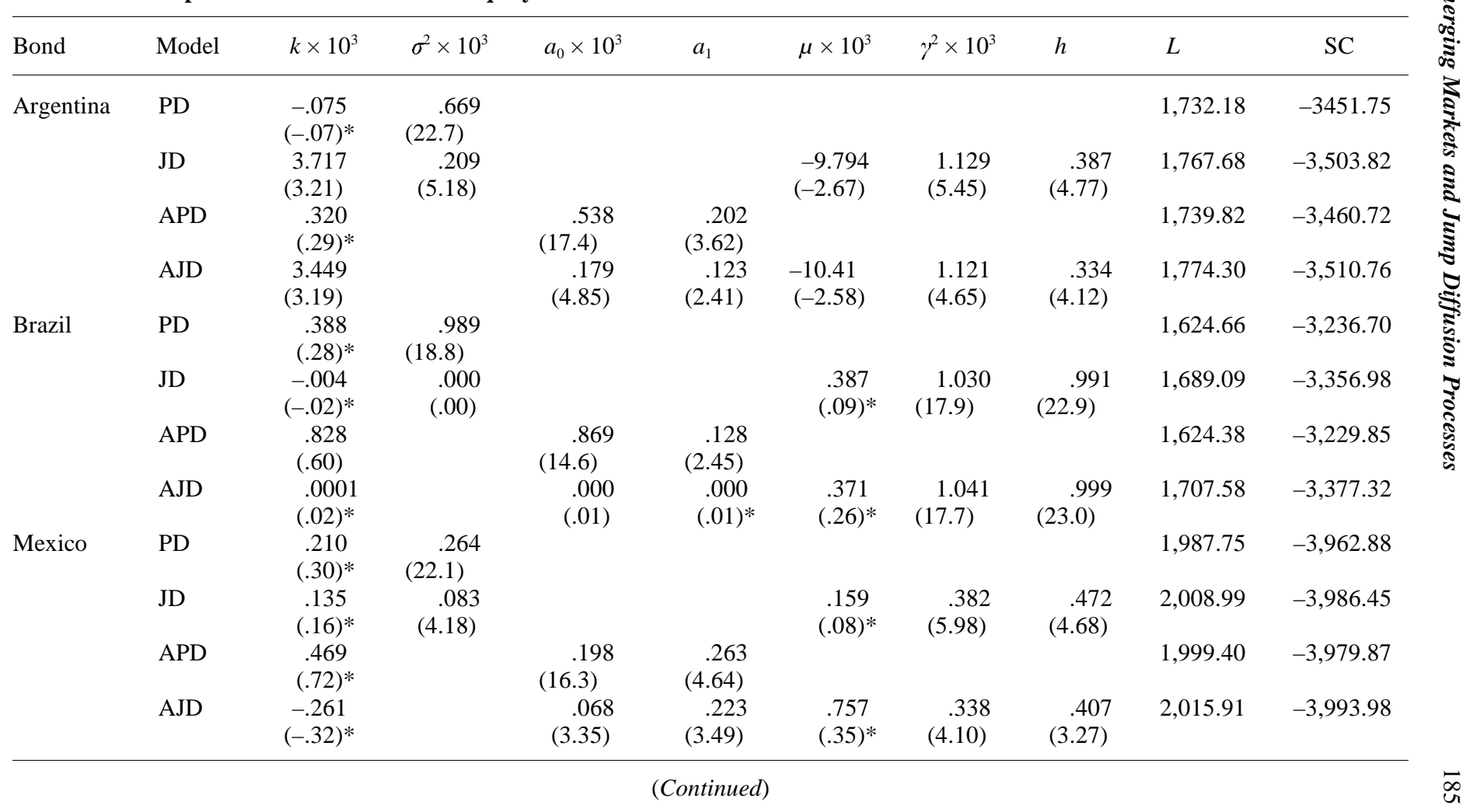




\section{TABLE 3. (Continued)}

\begin{tabular}{|c|c|c|c|c|c|c|c|c|c|c|}
\hline Bond & Model & $k \times 10^{3}$ & $\sigma^{2} \times 10^{3}$ & $a_{0} \times 10^{3}$ & $a_{1}$ & $\mu \times 10^{3}$ & $\gamma^{2} \times 10^{3}$ & $h$ & $L$ & $\mathrm{SC}$ \\
\hline \multirow[t]{4}{*}{ Peru } & PD & $\begin{array}{c}1.332 \\
(1.04)^{*}\end{array}$ & $\begin{array}{c}.528 \\
(17.9)\end{array}$ & & & & & & $1,113.04$ & $-2,214.42$ \\
\hline & JD & $\begin{array}{c}1.492 \\
(1.22)^{*}\end{array}$ & $\begin{array}{c}.108 \\
(3.61)\end{array}$ & & & $\begin{array}{l}-.320 \\
(-.10)^{*}\end{array}$ & $\begin{array}{r}.837 \\
(5.62)\end{array}$ & $\begin{array}{r}.501 \\
(5.75)\end{array}$ & $1,135.50$ & $-2,241.86$ \\
\hline & APD & $\begin{array}{c}.635 \\
(.49)^{*}\end{array}$ & & ${ }_{(15.2)}^{.425}$ & $\begin{array}{r}.208 \\
(2.48)\end{array}$ & & & & $1,115.46$ & $-2,213.45$ \\
\hline & AJD & $\begin{array}{c}.863 \\
(.75)^{*}\end{array}$ & & $\begin{array}{r}.092 \\
(3.33)\end{array}$ & $\begin{array}{r}.212 \\
(2.64)\end{array}$ & $\begin{array}{l}-.364 \\
(-.09)^{*}\end{array}$ & $\begin{array}{r}.845 \\
(4.75)\end{array}$ & $\begin{array}{r}.394 \\
(4.36)\end{array}$ & $1,138.79$ & $-2,242.63$ \\
\hline \multirow[t]{4}{*}{ Poland } & PD & $\begin{array}{c}5.349 \\
(2.59)\end{array}$ & $\begin{array}{c}1.417 \\
(18.4)\end{array}$ & & & & & & 945.10 & $-1,878.55$ \\
\hline & JD & $\begin{array}{r}-.745 \\
(-2.48)\end{array}$ & $\begin{array}{r}.009 \\
(6.03)\end{array}$ & & & $\begin{array}{l}10.83 \\
(2.76)\end{array}$ & $\begin{array}{c}2.450 \\
(8.95)\end{array}$ & $\begin{array}{c}.562 \\
(17.4)\end{array}$ & $1,099.99$ & $-2,170.84$ \\
\hline & APD & $\begin{array}{c}6.694 \\
(3.22)\end{array}$ & & $\begin{array}{c}1.280 \\
(16.1)\end{array}$ & $\begin{array}{r}.098 \\
(2.31)\end{array}$ & & & & 944.67 & $-1,871.87$ \\
\hline & AJD & $\begin{array}{r}-.670 \\
(-2.25)\end{array}$ & & $\begin{array}{c}.011 \\
(5.38)\end{array}$ & $\begin{array}{c}-.006 \\
(-1.76)^{*}\end{array}$ & $\begin{array}{l}10.87 \\
(2.72)\end{array}$ & $\begin{array}{c}2.484 \\
(8.73)\end{array}$ & $\begin{array}{c}.556 \\
(16.9)\end{array}$ & $1,097.69$ & $-2,160.42$ \\
\hline \multirow[t]{4}{*}{ Venezuela } & PD & $\begin{array}{c}-1.046 \\
(-.93)^{*}\end{array}$ & $\begin{array}{c}.433 \\
(23.0)\end{array}$ & & & & & & $1,146.68$ & $-2,281.70$ \\
\hline & JD & $\begin{array}{l}-.112 \\
(-.11)^{*}\end{array}$ & $\begin{array}{r}.197 \\
(6.23)\end{array}$ & & & $\begin{array}{c}-5.183 \\
(-.73)^{*}\end{array}$ & $\begin{array}{c}1.296 \\
(2.98)\end{array}$ & $\begin{array}{r}.180 \\
(2.52)\end{array}$ & $1,176.05$ & $-2,322.95$ \\
\hline & APD & $\begin{array}{c}-1.603 \\
(-1.34)^{*}\end{array}$ & & $\begin{array}{c}.338 \\
(15.1)\end{array}$ & $\begin{array}{r}.250 \\
(4.13)\end{array}$ & & & & $1,150.81$ & $-2,284.15$ \\
\hline & AJD & $\begin{array}{c}.141 \\
(1.26)^{*}\end{array}$ & & $\begin{array}{c}.000 \\
(.10)\end{array}$ & $\begin{array}{r}.224 \\
(3.43)\end{array}$ & $\begin{array}{c}-1.326 \\
(-.97)^{*}\end{array}$ & $\begin{array}{c}.422 \\
(14.3)\end{array}$ & $\begin{array}{l}.817 \\
(20.2)\end{array}$ & $1,170.26$ & $-2,305.57$ \\
\hline
\end{tabular}


TABLE 3. (Continued)

\begin{tabular}{|c|c|c|c|c|c|c|c|c|c|c|}
\hline Bond & Model & $k \times 10^{3}$ & $\sigma^{2} \times 10^{3}$ & $a_{0} \times 10^{3}$ & $a_{1}$ & $\mu \times 10^{3}$ & $\gamma^{2} \times 10^{3}$ & $h$ & $L$ & $\mathrm{SC}$ \\
\hline \multirow[t]{4}{*}{ LAMR } & PD & $\begin{array}{l}.334 \\
(.59)^{*}\end{array}$ & $\begin{array}{l}.170 \\
(23.5)\end{array}$ & & & & & & $2,108.59$ & $-4,204.57$ \\
\hline & JD & $\begin{array}{l}1.081 \\
(1.67)^{*}\end{array}$ & $\begin{array}{c}.112 \\
(7.95)\end{array}$ & & & $\begin{array}{c}-5.254 \\
(-1.34)^{*}\end{array}$ & $\begin{array}{r}.379 \\
(2.64)\end{array}$ & $\begin{array}{c}.142 \\
(1.92)^{*}\end{array}$ & $2,125.48$ & $-4,219.41$ \\
\hline & APD & $\begin{array}{c}.665 \\
(1.21)^{*}\end{array}$ & & $\begin{array}{c}.123 \\
(21.6)\end{array}$ & $\begin{array}{r}.299 \\
(5.09)\end{array}$ & & & & $2,121.21$ & $-4,223.50$ \\
\hline & AJD & $\begin{array}{c}.528 \\
(.71)^{*}\end{array}$ & & $\begin{array}{r}.006 \\
(1.10)\end{array}$ & $\begin{array}{r}.252 \\
(4.36)\end{array}$ & $\begin{array}{l}-.212 \\
(-.20)^{*}\end{array}$ & $\begin{array}{c}.147 \\
(15.2)\end{array}$ & $\begin{array}{c}.828 \\
(15.2)\end{array}$ & $2,127.66$ & $-4,217.48$ \\
\hline \multirow[t]{4}{*}{ USR } & PD & $\begin{array}{c}.301 \\
(1.27)^{*}\end{array}$ & $\begin{array}{l}.030 \\
(24.2)\end{array}$ & & & & & & $2,590.75$ & $-5,168.88$ \\
\hline & JD & $\begin{array}{c}.671 \\
(2.55)\end{array}$ & $\begin{array}{r}.015 \\
(6.55)\end{array}$ & & & $\begin{array}{l}-1.542 \\
(-1.42)^{*}\end{array}$ & $\begin{array}{r}.059 \\
(3.89)\end{array}$ & $\begin{array}{r}.240 \\
(2.85)\end{array}$ & $2,614.88$ & $-5,198.21$ \\
\hline & APD & $\begin{array}{c}.418 \\
(1.75)^{*}\end{array}$ & & $\begin{array}{c}.027 \\
(18.5)\end{array}$ & $\begin{array}{c}.103 \\
(2.97)\end{array}$ & & & & $2,589.58$ & $-5,160.24$ \\
\hline & AJD & $\begin{array}{c}.666 \\
(2.49)\end{array}$ & & $\begin{array}{r}.015 \\
(6.16)\end{array}$ & $\begin{array}{c}.011 \\
(.40)^{*}\end{array}$ & $\begin{array}{c}-1.518 \\
(-1.38)^{*}\end{array}$ & $\begin{array}{r}.058 \\
(3.72)\end{array}$ & $\begin{array}{r}.239 \\
(2.76)\end{array}$ & $2,609.52$ & $-5,181.91$ \\
\hline
\end{tabular}

Note: PD is for pure diffusion, JD for jump diffusion, APD for ARCH pure diffusion, and AJD for ARCH jump diffusion. The AJD model is specified as $X(t)=k+\sigma z(t)+J \times y, \sigma^{2}(t)=a_{0}+a_{l}(X(t-1)-k)^{2}$, where $z(t)$ is an i.i.d. standard normal error, $J$ is a Bernoulli random variable $(J=$ 1 with probability $h$ and $J=0$ with probability $1-h$ ), and $y$ is normally distributed with mean $\mu$ and variance $\gamma^{2}$. For the PD and APD models $h=0$, and for the JD model $\sigma^{2}(t)=\sigma^{2}$. L is for the log-likelihood and SC for the Schwartz criterion. The estimation of the parameters of the four diffusion processes is based on the maximum-likelihood estimation method. $t$-statistics are presented in the parentheses. *Statistically insignificant at the five percent level. The data are daily and cover the period March 2, 1992 to April 8, 1994. 


\section{B. Jump Diffusion Models with Time-Varying Jump Size}

Table 4 presents the results of estimating a jump diffusion model with time-varying jump sizes for bonds, as specified by equation 5 . According to equation 5, the mean jump size for bond returns is specified as a function of contemporaneous, one-day lagged, and oneday forward daily returns on the Federal Funds Rate, returns on the home country stock index, and returns on the U.S. equity market.

As shown in table 4, the coefficients of contemporaneous home country equity returns are positive and statistically significant for all sovereign bond returns. This implies that if there is a jump in the country's bond returns, the mean size of this jump is positively correlated to the performance of the home country equity index. In other words, a positive shock in the home country stock market is correlated with a positive shock in its bond returns and vice versa.

For most of the bonds, the return on the U.S. equity index is significantly, positively correlated to the mean jump size. A $1 \%$ increase in the return of the Mexican stock index will cause an increase of $.23 \%$ in the mean jump size of the Mexico Par bond on the same day. Similarly, a $1 \%$ decline in the return of the U.S. equity index will cause a decline of .64\% in the mean jump size of the same bond. In addition, the lagged return of the U.S. equity index has a positive and significant effect on shocks in the emerging markets, i.e., the shock from the U.S. equity index is experienced in these markets on the next day, too. The only exceptions are the Mexican bonds, where a jump in the U.S. equity index is fully impounded on the same day (with no lag effects). Given the evidence that the home country lagged equity index is insignificant in explaining mean jump size, we infer that emerging bond markets react faster to shocks in the home country equity markets than shocks in the U.S. equity markets. Finally, the return on federal funds is not significant in determining the size of the jump.

A possible explanation for this finding is that these sovereign bonds carry significant country risk. About half of the bonds in the sample have no underlying collateral (registered loans) and the other half have principal backed by U.S. treasury securities and a rolling interest guarantee. Since these bonds carry significant default risk (most of the registered loans have defaulted on interest payments; more information on each bond is contained in appendix A), their behavior would resemble that of a residual claim. Taking this logic a step further, these bonds would display equity characteristics and therefore the bond shocks are correlated with shocks in the home country equity market. 
TABLE 4. Jump Diffusion With Time Varying Mean Jump for Bond Returns

\begin{tabular}{|c|c|c|c|c|c|c|c|c|}
\hline & $\begin{array}{l}\text { Brazil } \\
\text { Exit }\end{array}$ & $\begin{array}{l}\text { Brazil } \\
\text { IDU }\end{array}$ & $\begin{array}{l}\text { Mexico } \\
\text { Discount }\end{array}$ & $\begin{array}{l}\text { Mexico } \\
\text { Par }\end{array}$ & $\begin{array}{l}\text { Peru } \\
\text { CB }\end{array}$ & Poland & $\begin{array}{l}\text { Venezuela } \\
\text { Discount }\end{array}$ & $\begin{array}{l}\text { Venez. } \\
\text { Par }\end{array}$ \\
\hline \multirow[t]{2}{*}{$k \times 10^{3}$} & .470 & .445 & .378 & 1.089 & 2.573 & -.209 & .038 & 1.251 \\
\hline & $(2.51)$ & $(1.01)^{*}$ & $(3.27)$ & $(5.40)$ & $(1.73)^{*}$ & $(-.34)^{*}$ & $(.05)^{*}$ & (1.99) \\
\hline \multirow[t]{2}{*}{$\sigma^{2} \times 10^{3}$} & .007 & .017 & .003 & .011 & .226 & .030 & .064 & .061 \\
\hline & (9.67) & (4.49) & $(8.11)$ & $(9.41)$ & $(5.71)$ & (4.30) & $(4.46)$ & (6.63) \\
\hline \multirow[t]{2}{*}{$h$} & .375 & .496 & .397 & .276 & .368 & .511 & .411 & .276 \\
\hline & $(12.5)$ & (7.88) & $(12.3)$ & $(8.55)$ & $(5.84)$ & (8.38) & (5.19) & $(5.02)$ \\
\hline \multirow[t]{2}{*}{$\gamma^{2} \times 10^{3}$} & $\begin{array}{ll}3 & .312\end{array}$ & .121 & .088 & .159 & .884 & .343 & .318 & .280 \\
\hline & (11.9) & (10.7) & (11.3) & $(7.75)$ & $(4.56)$ & $(8.23)$ & $(5.48)$ & (5.16) \\
\hline \multirow[t]{2}{*}{$c_{0}$} & .031 & .017 & -.001 & .027 & .146 & .018 & .019 & .004 \\
\hline & $(1.94)^{*}$ & $(1.15)^{*}$ & $(-.01)^{*}$ & (2.09) & $(2.83)$ & $(.75)^{*}$ & $(.59)^{*}$ & $(.90)^{*}$ \\
\hline \multirow[t]{2}{*}{$c_{1}$} & -107.21 & -135.17 & $92.34-$ & -290.37 & 66.72 & 227.57 & 279.75 & 221.71 \\
\hline & $(-.33)^{*}$ & $(-.52)^{*}$ & $\quad(.91)^{*}$ & $(-1.57)^{*}$ & $(.07)^{*}$ & $(.79)^{*}$ & $(.82)^{*}$ & $(.27)^{*}$ \\
\hline \multirow[t]{2}{*}{$c_{2}$} & -226.73 & 37.84 & -113.16 & $-19.98-1$ & 1357.4 & -124.87 & -41.86 & 331.65 \\
\hline & $(-.61)^{*}$ & $(.20)^{*}$ & $(-1.14)^{*}$ & $(-.15)^{*}$ & $(-1.37)^{*}$ & $(-.38)^{*}$ & $(-.12)^{*}$ & $(.42)^{*}$ \\
\hline \multirow[t]{2}{*}{$c_{3}$} & -34.78 & -97.12 & 20.58 & -30.84 & -377.40 & -297.75 & $-447.32-$ & -636.70 \\
\hline & $(-.11)^{*}$ & $(-.48)^{*}$ & $(.15)^{*}$ & $(-.21)^{*}$ & $(-.53)^{*}$ & $(-.78)^{*}$ & $(-.96)^{*}$ & $(-.67)^{*}$ \\
\hline \multirow[t]{2}{*}{$d_{1}$} & .130 & .155 & .133 & .234 & .323 & .292 & .371 & .347 \\
\hline & $(2.72)$ & (4.18) & $(2.55)$ & (3.49) & (2.05) & $(3.46)$ & (3.55) & (2.49) \\
\hline \multirow[t]{2}{*}{$d_{2}$} & .031 & .052 & .055 & .057 & -.081 & -.005 & -.047 & -.019 \\
\hline & $(.75)^{*}$ & $(1.29) *$ & $(1.40)^{*}$ & $(.89)^{*}$ & $(-.65)^{*}$ & $(-.07)^{*}$ & $(-.47)^{*}$ & $(-.13)^{*}$ \\
\hline \multirow[t]{2}{*}{$d_{3}$} & -.032 & .033 & .073 & .066 & .133 & .084 & .162 & .117 \\
\hline & $(-.72) *$ & $(.97)^{*}$ & $(1.60)^{*}$ & $(.91)^{*}$ & $(.63)^{*}$ & $(1.21)^{*}$ & $(1.48)^{*}$ & $(.99)^{*}$ \\
\hline \multirow[t]{2}{*}{$e_{1}$} & .074 & .730 & .164 & .645 & 3.604 & .530 & 1.047 & 2.234 \\
\hline & $(.26)^{*}$ & (3.68) & $(1.52)^{*}$ & (3.04) & $(6.46)$ & $(1.80)^{*}$ & $(2.62)$ & (3.08) \\
\hline \multirow[t]{2}{*}{$e_{2}$} & .518 & .325 & .095 & .211 & 1.350 & .591 & .469 & 1.148 \\
\hline & $(1.65)^{*}$ & (1.99) & $(.64)^{*}$ & $(.80)^{*}$ & $(2.29)$ & $(1.59)^{*}$ & $(1.42)^{*}$ & $(2.21)$ \\
\hline \multirow[t]{2}{*}{$e_{3}$} & .261 & -.114 & -.010 & .238 & -1.333 & .176 & .400 & .680 \\
\hline & $(1.21)^{*}$ & $(-.78)^{*}$ & $(-.08)^{*}$ & $(1.07)^{*}$ & $(-2.40)$ & $(.055)^{*}$ & $(1.13)^{*}$ & $(1.24)^{*}$ \\
\hline $\log \mathrm{L}$ & 2349.56 & 1632.73 & $2650.32 \quad 2$ & $2491.76 \quad 1$ & 1085.9 & $1294.13 \quad 1$ & $1281.76 \quad 1$ & 1327.65 \\
\hline
\end{tabular}

Note: The jump diffusion process is specified as $x(t)=k+\sigma z(t)+J \times y$, where $z(t)$ is an i.i.d. standard normal error, $J=1$ with a probability of $h$ and $J=0$ with probability $1-h$, $y$ is normally distributed with mean $\mu(t)$ and variance $\gamma^{2}$, and $\mu(t)=c_{0}+c_{1} F F F_{t}+c_{2} F F F_{t-1}$ $+c_{3} F F F_{t+1}+d_{1} H S R_{t}+d_{2} H S R_{t-1}+d_{3} H S R_{t+1}+e_{1} U S R_{t}+d_{2} U S R_{t-1}+d_{3} U S R_{t+1} . F F R_{t}$ is the Federal Funds Rate, $H S R_{t}$ is the home country equity index return, and $U S R_{t}$ is the U.S. equity stock index return. The data are daily and cover the period March 2, 1992 to April 8, 1994. Estimation is carried out using the maximum-likelihood method. T-statistics are presented in the parentheses. *Statistically insignificant at the five perecnet level.

This hypothesis is further supported by evidence that the U.S. equity market return is significant in explaining the mean jump size in the bond market while the U.S. interest rate is not.

Table 5 presents results when mean jump size in country equity 
TABLE 5. Jump Diffusion With Time Varying Mean Jump for Equity Returns

\begin{tabular}{|c|c|c|c|c|c|c|c|}
\hline & Argentina & Brazil & Mexico & Peru & Poland & Venezuela & a LAMR \\
\hline \multirow[t]{2}{*}{$k \times 10^{3}$} & 4.549 & -.011 & -.107 & 1.123 & -.745 & -.460 & .656 \\
\hline & $(3.47)$ & $(-.01)^{*}$ & $(-.11)^{*}$ & $(.86)^{*}$ & $(-2.49)$ & $(-.42)^{*}$ & $(.58)^{*}$ \\
\hline \multirow[t]{2}{*}{$\sigma^{2} \times 10^{3}$} & .196 & .00 & .038 & .099 & .009 & .193 & .046 \\
\hline & $(6.75)$ & $(.00)^{*}$ & (3.07) & (3.04) & $(6.02)$ & (7.33) & (3.39) \\
\hline \multirow[t]{2}{*}{$h$} & .463 & .977 & .699 & .552 & .563 & .203 & .690 \\
\hline & $(7.50)$ & (18.8) & (11.13) & $(5.46)$ & $(17.4)$ & $(3.48)$ & (9.07) \\
\hline \multirow[t]{2}{*}{$\gamma^{2} \times 10^{3}$} & .664 & .816 & .245 & .674 & 2.215 & .582 & .106 \\
\hline & $(7.67)$ & (14.4) & $(10.6)$ & $(5.46)$ & $(8.79)$ & $(2.15)$ & (5.09) \\
\hline \multirow[t]{2}{*}{$c_{0}$} & .003 & .027 & .002 & -.023 & .145 & -.031 & .004 \\
\hline & $(.11)^{*}$ & $(1.12)^{*}$ & $=(.22)^{*}$ & $(-.62)^{*}$ & $\quad(2.97)$ & $(-.50)^{*}$ & $* \quad(.56)^{*}$ \\
\hline \multirow[t]{2}{*}{$c_{1}$} & -375.6 & 157.04 & -162.78 & 544.49 & -168.58 & 565.71 & -82.84 \\
\hline & $(-1.07)^{*}$ & $(.55)^{*}$ & $(-1.12)^{*}$ & $(.94)^{*}$ & $(-.18)^{*}$ & $\quad(.37)^{*}$ & * $\quad(-.74)^{*}$ \\
\hline \multirow[t]{2}{*}{$c_{2}$} & 159.27 & -152.29 & 249.99 & 134.44 & -907.44 & -590.40 & 176.89 \\
\hline & $(.44)^{*}$ & $(-.55)^{*}$ & $=(1.85)^{*}$ & $\quad(.32)^{*}$ & $=(-1.34)^{*}$ & $=(-.44)^{*}$ & * $\quad(1.65)^{*}$ \\
\hline \multirow[t]{2}{*}{$c_{3}$} & 66.94 & -308.13 & -109.77 & -409.14 & -468.82 & 409.86 & -150.06 \\
\hline & $(.28)^{*}$ & $(-1.02)^{*}$ & $=(-.74)^{*}$ & $(-.86)^{*}$ & $=(-.51)^{*}$ & $(.28)^{*}$ & * $(-1.43)^{*}$ \\
\hline \multirow[t]{2}{*}{$d_{1}$} & 3.142 & .972 & .764 & .186 & .097 & 1.136 & .651 \\
\hline & $(4.83)$ & (6.65) & (5.85) & $(2.44)$ & $(.61)^{*}$ & (3.29) & (8.38) \\
\hline \multirow[t]{2}{*}{$d_{2}$} & .177 & -.085 & .105 & .154 & .179 & .991 & .005 \\
\hline & $(.47)^{*}$ & $(-.52) *$ & $(.73)^{*}$ & (1.98) & $(.81)^{*}$ & $(2.11)$ & $(.06)^{*}$ \\
\hline \multirow[t]{2}{*}{$d_{3}$} & 2.011 & .343 & .092 & .097 & .064 & .023 & .177 \\
\hline & $(3.19)$ & $(2.47)$ & $(.83)^{*}$ & $(1.26)^{*}$ & $(.29)^{*}$ & $(.06)^{*}$ & $(2.16)$ \\
\hline \multirow[t]{2}{*}{$e_{1}$} & .442 & .221 & 1.01 & -.074 & .591 & -1.737 & .761 \\
\hline & $(.96)^{*}$ & $(.79)^{*}$ & $(5.63)$ & $(-.17)^{*}$ & $(.89)^{*}$ & $(-2.31)$ & $(5.27)$ \\
\hline \multirow[t]{2}{*}{$e_{2}$} & .500 & -.168 & .152 & .269 & .811 & -1.212 & .205 \\
\hline & $(1.30)^{*}$ & $(-.56)^{*}$ & $(.84)^{*}$ & $(.59)^{*}$ & $(1.29)^{*}$ & $(-.78)^{*}$ & $(1.42)^{*}$ \\
\hline \multirow[t]{2}{*}{$e_{3}$} & .229 & .004 & .121 & -.322 & 1.015 & -.304 & -.045 \\
\hline & $(.47)^{*}$ & $(.01)^{*}$ & $\quad(.73)^{*}$ & $\quad(-.66)^{*}$ & $\quad(1.18)^{*}$ & $\quad(-.23)^{*}$ & $* \quad(-.39)^{*}$ \\
\hline$L$ & $1,753.33$ & $1,184.61$ & $2,015.74$ & $1,125.52$ & $1,109.53$ & $1,187.022$ & $2,079.11$ \\
\hline
\end{tabular}

Note: The jump diffusion process is specified as $x(t)=k+\sigma z(t)+J \times y$, where $z(t)$ is an i.i.d. standard normal error, $J=1$ in a case of a jump with a probability of $h$ and $J=0$ in case of no jump with probability $1-h, y$ is normally distributed with mean $\mu(t)$ and variance $\gamma^{2}$, and $\mu(t)=c_{0}+c_{1} F F F_{t}+c_{2} F F F_{t-1}+c_{3} F F F_{t+1}+d_{1} H B R_{t}+d_{2} H B R_{t-1}+d_{3}$ $H B R_{t+1}+e_{1} U S R_{t}+\mathrm{d}_{2} U S R_{t-1}+d_{3} U S R_{t+1} . F F R_{t}$ is the Federal Funds Rate, $H B R_{t}$ is the home country bond return, and $U S R_{t}$ is the U.S. equity stock index return. The data are daily and cover the period March 2, 1992 to April 8, 1994. Estimation is carried out using maximum likelihood method. $\mathrm{t}-$ statistics are presented in the parentheses. *Statistically insignificant at the five percent level.

returns is a function of contemporaneous, lagged, and forward returns on the Fed Fund Rate, returns on the bond(s) issued by that country, and U.S. value-weighted equity returns. The bond returns are positively 
related to mean jump size for all countries except Poland, while the effects of the U.S. equity index returns are mixed. Clearly, there is a connection between the bond market and equity market in the same country, i.e., both markets experience shocks at the same time. However, the U.S. stock market is related to jumps in the emerging bond markets but not in the emerging stock markets. An explanation for this phenomenon may be the trading location. The emerging bonds are traded predominantly in New York and London while the stock indices are traded only in the home countries. Shocks in the U.S. equity market may affect traders in the emerging bond markets more because these traders are closer to the source of the shocks than traders in the emerging equity markets.

In sum, this article suggests that both bond and equity markets in emerging countries carry significant country risk and that the emerging bonds in this article also have exposure to the U.S. equity market.

\section{Summary and Conclusions}

It is well known that emerging financial markets are extremely volatile. Given the conjecture that extreme values in the data may be due to sporadic releases of information, this article employs the pure diffusion, jump diffusion, ARCH pure diffusion, and ARCH jump diffusion models to model the daily return series of several emerging bond and stock markets. In addition, it attempts to identify some sources of information surprises in emerging stock and bond markets.

The results show that the ARCH jump diffusion model fits the data better than a pure diffusion model, and the jump diffusion model performs better than both the pure diffusion and $\mathrm{ARCH}$ pure diffusion models. Also, shocks in the U.S. value-weighted equity index relate to shocks in the emerging bond market but not shocks in the individual country equity market.

These results have important implications for risk management, asset allocation strategies, hedging, and pricing of derivatives in these markets. For example, risk measures such as Value at Risk depend on correct specification of the return distribution. As shown by Duffie and Pan (1997), different distributions produce different VARs and different predictions of extreme events. The adequacy of risk-reserve capital that is based on these estimates depends on the correctness of the distribution assumption. Our results suggest that jump diffusion may be 
used for modeling bonds and equities from emerging markets.

Furthermore, identification of the appropriate empirical distribution and sources of jumps in the emerging markets allows the choice of more appropriate models for pricing options on emerging market securities. ${ }^{15}$ This has become especially useful since in 1996 the Chicago Mercantile Exchange introduced options on Brady Bonds issued by Argentina, Brazil, and Mexico, which are included in our sample. In addition, the results on jump risk sources can serve as a guide in selecting hedging strategies for investors, who want exposure to only specific country risk factors, as opposed to risk from U.S. interest rates and stock markets.

The findings in this article open several avenues for future research. First, there is a need for derivative pricing models which do not assume that the jump risk is diversifiable. Secondly, these results establish the need for a theoretical model other than the mean-variance framework for implementing asset allocation strategies when returns of the underlying security do not follow the normal distribution. Finally, it would be interesting to compare the performance of VAR estimation using jump diffusion to approximate the distribution to VAR estimation using tail distribution.

\section{Appendix A}

\section{Bond Descriptions}

\section{Brazil Exit}

These bonds, issued on August 31, 1989, mature on September 15, 2013. They carry a fixed interest rate of $6 \%$ and the issue size was $\$ 1.1$ billion. The repayment is in the form of a pro-rata sinking fund and these bonds are eligible for debt equity conversion. They are registered loans and neither principal nor interest is collateralized.

\section{Brazil IDU}

The Interest-Due-and-Unpaid bonds were issued by the Federative Republic of Brazil on November 20, 1992, retroactively to January 1, 1991. These bonds mature on January 1, 2001. The face value of all outstanding IDUs is approximately US-\$7 billion. The coupon is step-up/floating: $7.813 \%$ to $1 / 92$,

15. Merton (1976a, 1976b) and Naik and Lee (1990) provide a model to compute option prices when the underlying stochastic process is a jump diffusion process. 
$8.375 \%$ to $1 / 93,8.750 \%$ to $1 / 94$ and 6 -month LIBOR to $1 / 2001$ and is paid semi-annually. Neither principal nor interest is collateralized.

\section{Mexico Par Bonds}

These bonds were issued as part of Mexico's debt restructuring program. They were exchanged for outstanding debt on March 28, 1990. Approximately $\$ 16.8$ billion worth of bonds were issued. The bonds are denominated in U.S. dollars and have a face value of $\$ 250,000$. They are registered on the Luxembourg stock exchange but are governed by the law of the State of New York. The bonds pay a fixed coupon of $6.25 \%$ on a semi-annual basis. They mature on December 31, 2019. The coupon dates are March 30 and September 30. Interest is collateralized by a deposit of 18 months of interest payments. Principal is fully collateralized by U.S. Treasury zero-coupon bonds and is payable in full at maturity. The bonds also include a call feature that permits the Mexican government to retire them by paying the principal and accrued interest on any coupon date. Starting on July 1, 1996, in addition to the coupon payments, the holders of these bonds are eligible to receive quarterly payments based on Mexican oil exports. However, these payments cannot exceed 30\% of Mexico's quarterly oil exports.

\section{Mexico Discount}

These bonds were also issued as part of the Mexican debt restructuring program. Approximately $\$ 8.3$ billion worth of bonds were issued at a discount of 35\%. They are similar to the Mexico Par bonds described above with the exception that they make variable coupons which are set at a premium of 13/16 over the 6-month LIBOR, and these coupon payments are collateralized at an interest rate of $10 \%$.

\section{Morocco}

The tranche A of the restructuring and consolidation of debt as an outcome of the 1985-88 refinancing agreement was issued on September 20, 1990. The bond matures on January 1, 2009, and the issue size was $\$ 2.8$ billion. The bond has a floating rate coupon 6-month LIBOR+0.8125\% and repayment is in the form of a pro-rata sinking fund. This is a sovereign loan guaranteed by the Kingdom of Morocco. It has no underlying collateral.

\section{Nigeria Par}

Approximately \$2.1 billion of these bonds were issued on January 21, 1992 in exchange for outstanding debt. The bonds mature on November 15, 2020. They are also registered on the Luxembourg Stock Exchange, and are governed by English Law. Their principal, $\$ 250,000$, is fully collateralized by U.S. zerocoupon Treasury bonds and repayable in full at maturity. The semi-annual 
coupon payments on these bonds were made at the rate of $5.5 \%$ until January 1995 , at which point the coupon rate increased to $6.25 \%$. Interest payments are collateralized for 12 months at a rate of $6.25 \%$. The collateral is on deposit at the Bank of England. Like the Mexican bonds, these bonds are callable for face value plus accrued interest. Oil-indexed payment adjustment coupons were also issued with each bond. Each coupon has a face value of $\$ 1,000$. Beginning in November 1996, each coupon entitled the holder to a payment based on the amount by which the average price of "Bonny Light" oil six months prior to the payments date exceeds $\$ 28$, a reference price which will be adjusted for inflation each payment period. These semi-annual payments are not to exceed $\$ 15$ per coupon and are subject to cancellation if Nigerian crude oil output for the six months preceding a coupon date falls below $92.5 \%$ of the base production of 1.74 million barrels per day.

\section{Panama}

This is a registered loan guaranteed by the Republic of Panama. This loan was issued on October 31, 1985, and matured on September 30, 1997. The issue size was $\$ 0.6$ billion and it carried a floating coupon of 6-month LIBOR plus $1.375 \%$. This bond had no underlying collateral and has not been serviced since March 1988.

\section{Peru $C B$}

This is a sovereign loan issued by the Republic of Peru. The approximate issue size is $\$ .8$ billion. This loan is an outcome of a credit agreement reached on May 31, 1983. The bond's maturity date was July 31, 1991. The bond has not been serviced since and it is currently under default. It has a coupon rate of US prime plus $2.25 \%$ or LIBOR plus $2.25 \%$.

\section{Poland DDRA}

The issue size of the Poland Debt Deferral and Restructure Agreement was $\$ 8.44$ billion. They were issued on July 20, 1988, and mature on December 31, 2002. The coupon rate is 6-month LIBOR $+.8125 \%$ and repayment is in the form of a bullet. The bond is a registered loan with Dresdner Bank as the international agent. Neither principal nor interest is collateralized. Interest has not been paid since January 4, 1989. Accrued and unpaid interest was estimated at 23\% as of February 2, 1993.

\section{Venezuela Par}

Approximately $\$ 6.6$ billion of Venezuela Par bonds were issued on December 18, 1990, in exchange for outstanding debt. The bonds mature on March 31, 2020, and resemble the Mexican par bonds except for their coupon payments, interest guarantees, and oil-related payments. The coupon rate for these bonds 
is fixed at $6.75 \%$ and is collateralized by a deposit covering 14 months of interest. Each bond was issued with five oil-indexed payment obligations per $\$ 1,000$ of face value. Beginning with the coupon payment in April 1996, on the date of each subsequent coupon payment, each payment obligation entitles the holder to a payment equal to the difference between the average price for Venezuelan crude for the preceding 12 months and \$26. The strike price of $\$ 26$ will be adjusted to reflect the U.S. inflation rate. The payments are not to exceed \$3/obligation and are subject to suspension of the payments on these obligations if the volume of oil exports declines by more than $7.75 \%$. However, payments will be allowed to accrue and will earn interest at the LIBOR.

\section{Venezuela Discount}

On December 18, 1990, approximately $\$ 1.18$ billion of these bonds were issued at a discount of $30 \%$ in exchange for outstanding debt. The bonds are virtually identical to the Venezuela Par bonds described above with the exception that their coupons pay a premium of $13 / 16 \%$ over LIBOR and are collateralized by a deposit equaling 14 months' interest at $9.75 \%$.

\section{Appendix B}

\section{Derivation of the Likelihood Function}

In ARCH jump diffusion model the returns at time $t$ are specified as

$$
\begin{gathered}
X(t)=k+\sigma(t) z(t)+J \times y, \text { and } \\
\sigma^{2}(t)=a_{0}+a_{1}[X(t-1)-k]^{2},
\end{gathered}
$$

where $z(t)$ is i.i.d. standard normal, $J$ is a Bernoulli random variable taking the value of $(J=1)$ in the case of a jump with probability $h$ and the value of zero $(J=0)$ in the acse of no jump with probability $1-h$. The random variable $y$ is normally distributed with mean $\mu$ and variance $\gamma^{2}$ and it is stochastically independent of $z(t)$. The parameters to be estimated are $k, a_{0}, a_{1}, h, \mu$ and $\gamma^{2}$. The likelihood of each $X(t)$, conditional on the values for the parameters is,

$$
\begin{aligned}
P(X(t))= & P(J=0) \times f(X(t) \mid J=0) \\
& +P(J=1) \times f(X(t) \mid J=1)
\end{aligned}
$$




$$
\begin{aligned}
& =\frac{1-h}{\sqrt{2 \pi \sigma(t)^{2}}} \exp \left(-\frac{1}{2} \frac{(X(t)-k)^{2}}{\sigma(t)^{2}}\right) \\
& +\frac{h}{\sqrt{2 \pi\left(\sigma(t)^{2}+\gamma^{2}\right)}} \exp \left(-\frac{1}{2} \frac{(X(t)-k-\mu)^{2}}{\left(\sigma(t)^{2}+\gamma^{2}\right)}\right) .
\end{aligned}
$$

The likelihood of the data series is the product of all $P(X(t))$ and the log likelihood is then expressed as equation 5 .

Note that in a jump diffusion without ARCH effects, $\sigma(t)^{2}$ is replaced by $\sigma^{2}$ and with ARCH effects by $a_{0}+a_{1}[X(t-1)-k]^{2}$. In a pure jump diffusion model, $\sigma^{2}$ is a parameter and the parameter space in a pure jump diffusion model contains $k, \sigma^{2}, h, \mu$, and $\gamma^{2}$. In an ARCH model, there is no jump, so $h$ is restricted to be 0 and $\mu$ and $\gamma^{2}$ are irrelevant. $\sigma^{2}$ still varies and the parameters in an ARCH model are then $k, a_{0}$, and $a_{1}$. In a pure diffusion model, the parameters to be estimated are only $k$ and $\sigma^{2}$.

\section{References}

Akgiray, V., and Booth, G. 1987. Conditional distribution models of stock returns: An empirical comparison. Journal of Financial Research 10(3): 269-280.

Ball, C., and Torous, W. 1983. A simplified jump process for common stock returns. Journal of Financial and Quantitative Analysis 18(1): 53-65.

Ball, C., and Torous, W. 1985. On jumps in common stock prices and their impact on call option pricing. Journal of Finance 40(1): 155-173.

Baillie, R., and Bollerslev, T. 1989. The message in daily exchange rates: A conditional variance tale. Journal of Business and Economic Statistics 7: 297-305.

Bollerslev, T.; Chou, R.; and Kroner, K. 1992. ARCH modeling in finance: A review of the theory and empirical evidence. Journal of Econometrics 52: 5-59.

Booth, G. G.; Broussard, J.P.; Martikainen, T.; and Puttonen, V. 1997. Prudent margin levels in the Finnish stock index futures market. Management Science 43: 1177-1188.

Chahal M.; Rebello, M.; and Smith, S. 1995. Emerging and developed debt markets: An exploratory investigation using daily data. Working paper. Georgia State University.

Claesseens, S., and Gooptu, S. 1993. Overview. In S. Claessens and S. Gooptu (eds). Portfolio Investment in Developing Countries. The World Bank 
Discussion Papers.

Das, S. 1995. Jump diffusion processes and the bond markets. Working paper. Harvard University.

Duffie, D., and Pan, J. 1997. An overview of value at risk. Journal of Derivative (spring): 7-49.

Embrechts, P.; Resnick, S.; and Samorodnitsky, G. 1998. Living on the edge. Risk (January), 96-101.

Harvey, C. 1995. Predictable risk and return in emerging markets. Review of Financial Studies 8: 773-816.

Jarrow, R., and Rosenfeld, E. 1984. Jump risks and intertemporal capital asset pricing model. Journal of Business 57: 337-351.

Johnson, G., and Schneeweis, T. 1994. Jump-diffusion processes in the foreign exchange markets and the release of macroeconomic news. Computational Economics 7: 309-329.

Jorion, P. 1988. On jump processes in the foreign exchange and stock markets. Review of Financial Studies 1(4): 427-445.

Kim, M.; Oh, Y.; and Brooks, R. 1994. Are jumps in stock returns diversifiable? Evidence and implication for option pricing. Journal of Financial and Quantitative Analysis 29: 609-631.

Merton, R. 1976a. Option pricing when underlying stock returns are discontinuous. Journal of Financial Economics 3(1/2): 125-144.

Merton, R. 1976b. The impact on option pricing of specification error in the underlying stock price returns. Journal of Finance 31: 333-350.

Merton, R. 1990. Continuous-Time Finance. Oxford: Basil Blackwell.

Naik, E., and Lee, M. 1990. General equilibrium pricing of options on the market portfolios with discontinuous returns. Review of Financial Studies 3: 493-521.

Schwarz, G. 1978. Estimating the dimension of a model. Annals of Statistics 6 : 461-464.

Theodossiou, P. 1999. Financial data and the skewed generalized t distribution. Management Science, forthcoming. 